\title{
Author Correction: Electrical fingerprint of the amygdala guides neurofeedback training for stress resilience
}

Jackob N. Keynan, Avihay Cohen, Gilan Jackont, Nili Green, Noam Goldway (D), Alexander Davidov, Yehudit Meir-Hasson, Gal Raz, Nathan Intrator, Eyal Fruchter, Keren Ginat, Eugene Laska, Marc Cavazza (D) and Talma Hendler (D)

Correction to: Nature Human Behaviour https://doi.org/10.1038/s41562-018-0484-3, published online 10 December 2018.

In the version of this article initially published, the funding information was incorrect. The sentence "The European Union's Seventh Framework Program (FP7-EU) for research, technological development and demonstration under grant agreement no. 602186." should not have been included. The error has been corrected in the HTML and PDF versions of the article.

Original:

We thank I. Rashap, D. Torjeman, Y. Roll, S. Dushy, I. Teshner, N. Shani, L. Frumer, T. Yeheskely, R. Bashan, L. Wiezman, O. Shani, A. Greental, T. Jacoby and M. Halevy for assisting in this study. This project was supported by the following grants: US Department of Defense-grant agreement no. W81XWH-11-2-0008. The European Union's Seventh Framework Programme (FP7-EU) for research, technological development and demonstration under grant agreement no. 602186. Mafat, IDF, I-Core cognitive studies grant agreement no. 693210. The funders had no role in study design, data collection and analysis, decision to publish or preparation of the manuscript.

Corrected:

We thank I. Rashap, D. Torjeman, Y. Roll, S. Dushy, I. Teshner, N. Shani, L. Frumer, T. Yeheskely, R. Bashan, L. Wiezman, O. Shani, A. Greental, T. Jacoby and M. Halevy for assisting in this study. This project was supported by the following grants: US Department of Defense-grant agreement no. W81XWH-11-2-0008; and Mafat, IDF, I-Core cognitive studies grant agreement no. 693210. The funders had no role in study design, data collection and analysis, decision to publish or preparation of the manuscript.

Published online: 28 January 2019

https://doi.org/10.1038/s41562-019-0534-5 